\title{
Drosophila melanogaster Hsp22: a mitochondrial small heat shock protein influencing the aging process
}

\author{
Geneviève Morrow and Robert M. Tanguay* \\ Laboratoire de Génétique Cellulaire et Développementale, Département de Biologie Moléculaire, Biochimie Médicale et \\ Pathologie, Institut de Biologie Intégrative et des Systèmes and PROTEO, Université Laval, Québec, QC, Canada
}

OPEN ACCESS

Edited by:

Alexey Moskalev,

Institute of Biology of Komi Science

Center of Ural Division of RAS, Russia

Reviewed by:

Seung-Jae Lee,

Pohang University of Science and Technology, South Korea

Fabio Demontis,

St. Jude Children's Research

Hospital, USA

*Correspondence:

Robert M. Tanguay,

Laboratoire de Génétique Cellulaire et

Développementale, Département de

Biologie Moléculaire, Biochimie

Médicale et Pathologie, Institut de

Biologie Intégrative et des Systèmes

and PROTEO, Université Laval,

Pavillon CE-Marchand, 1030 Avenue

de la Médecine, Québec

QC G1V OA6, Canada

robert.tanguay@ibis.ulaval.ca

Specialty section:

This article was submitted to Genetics

of Aging, a section of the journal

Frontiers in Genetics

Received: 27 January 2015

Paper pending published:

03 February 2015

Accepted: 27 February 2015

Published: 16 March 2015

Citation:

Morrow G and Tanguay RM (2015)

Drosophila melanogaster Hsp22: a

mitochondrial small heat shock

protein influencing the aging process.

Front. Genet. 6:103.

doi: 10.3389/fgene.2015.00103
Mitochondria are involved in many key cellular processes and therefore need to rely on good protein quality control (PQC). Three types of mechanisms are in place to insure mitochondrial protein integrity: reactive oxygen species scavenging by antioxidant enzymes, protein folding/degradation by molecular chaperones and proteases and clearance of defective mitochondria by mitophagy. Drosophila melanogaster Hsp22 is part of the molecular chaperone axis of the PQC and is characterized by its intra-mitochondrial localization and preferential expression during aging. As a stress biomarker, the level of its expression during aging has been shown to partially predict the remaining lifespan of flies. Since over-expression of this small heat shock protein increases lifespan and resistance to stress, Hsp22 most likely has a positive effect on mitochondrial integrity. Accordingly, Hsp22 has recently been implicated in the mitochondrial unfolding protein response of flies. This review will summarize the key findings on D. melanogaster Hsp22 and emphasis on its links with the aging process.

Keywords: Hsp22, Drosophila melanogaster, aging, mitochondria, mitochondrial unfolding protein response

\section{Introduction}

Aging is associated with a decline in protein homeostasis (proteostasis) that leads to the accumulation of deleterious protein damages. Mitochondrial proteins are particularly prone to accumulate damages due in part to the close proximity of the ETC. To circumvent deleterious accumulation of protein damages, three types of mechanisms are involved in mitochondrial PQC (reviewed in Kotiadis et al., 2014). The first line of defense comprises both anti-oxidants enzymes that scavenge ROS produced as by-product of the ETC and molecular chaperones and proteases that insure protein folding or degradation of damaged proteins (reviewed in Bozaykut et al., 2014). The third mechanism of mitochondrial PQC involves the clearance of highly damaged mitochondria through mitophagy (reviewed in Osellame and Duchen, 2014; Scheibye-Knudsen et al., 2015).

Heat shock proteins are molecular chaperones found in all organisms. They are subdivided in distinct families based on their molecular weight and sequence homology: HSP110, HSP90, HSP70, HSP60, HSP40, and sHSP. Each HSP family has specific functions that have been the subject of different reviews (Vos et al., 2008; Priya et al., 2013; Ryabova et al., 2013; Saibil, 2013; Karagoz and Rudiger, 2015). The sHSPs are characterized by the presence of the alpha-crystallin domain and are at the crossroad between two main process namely protein

Abbreviations: ETC, electron transport chain; HSE, heat shock element; HSP, heat shock protein; mtUPR, mitochondrial unfolding protein response; $\mathrm{PQC}$, protein quality control; ROS, reactive oxygen species; sHSP, small heat shock protein. 
folding and degradation. Indeed, most sHSPs have the ability to prevent protein aggregation and to maintain their client in a refoldable state hence preventing them to form deleterious interactions (reviewed in Haslbeck et al., 2005; McHaourab et al., 2009; Fu, 2014; Treweek et al., 2015). Additionally, some sHSPs are involved in protein degradation via the proteasome and autophagy (Goldbaum et al., 2009; Bissonnette et al., 2010; Acunzo et al., 2012).

In Drosophila melanogaster there are 12 members of the sHSP family that have different chaperone ability, distinctive intracellular localization and cell- and stage-specific pattern of expression (Michaud et al., 2002; Vos, 2009; Morrow and Tanguay, 2015). Almost all of them are stress-inducible, but only seven have been shown to be up-regulated during aging (CG14207, 1(2)efl, Hsp67Bc, Hsp22, Hsp23, Hsp26, and Hsp27; King and Tower, 1999; Zou et al., 2000; Landis et al., 2004, 2012; Wang et al., 2005; Girardot et al., 2006; Tanguay and Morrow, 2008; Yang and Tower, 2009). Among these sHSPs, the link between Hsp22 and aging is particularly interesting due to its peculiar mitochondrial matrix localization (Morrow et al., 2000) and given the central role of mitochondria in the aging process (Hill and Van Remmen, 2014; Ziegler et al., 2014). Mitochondria are involved in different metabolic and signaling pathways (ATP production, amino acid catabolism, fatty acid $\beta$-oxidation, apoptosis among others) and are in constant communication with the nucleus to adjust to metabolic demand (Haynes et al., 2007; Haynes and Ron, 2010; Runkel et al., 2014). While ROS produced by mitochondria have been at the center of the free radical theory of aging (Harman, 1956), recent reports are now showing that increased ROS production is not always harmful and can even promote longevity (Van Raamsdonk and Hekimi, 2009, 2012; Yee et al., 2014). In recent years, multiple factors have been shown to contribute to aging by favoring accumulation of dysfunctional mitochondria such as impairment of mitochondria-to-nucleus signaling, changes in mitochondrial dynamics (fusion/fission) and clonal amplification of mitochondrial DNA mutations (Bereiter-Hahn, 2014; Hepple, 2014; Ziegler et al., 2014). A failure to maintain mitochondrial homeostasis and integrity is therefore associated with aging (Bratic and Larsson, 2013; Bohovych et al., 2014) and accordingly, the maintenance of mitochondrial stress response has gained recognition as a potential pro-longevity mechanism (Hill and Van Remmen, 2014; Scheibye-Knudsen et al., 2015).

\section{Hsp22 is Preferentially Up-Regulated During Aging}

As a member of the sHSP family, Hsp22 is readily upregulated by a variety of different stresses (Colinet et al., 2010; Hirano et al., 2012; Landis et al., 2012; Morrow and Tanguay, 2015) but its developmental expression pattern is tightly regulated. Indeed, during development its expression is restricted to the metamorphosis of larvae to pupae (Michaud et al., 2002). However, during adulthood Hsp22 is the most up-regulated sHSP, the induction of its mRNA reaching up to $60 \%$ in the head of 30 days-old flies comparatively to 6 days-old flies (King and Tower, 1999; Yang and Tower, 2009; Landis et al., 2012). Since $h s p 22$ mRNA is post-transcriptionally regulated, the protein was only detected starting at 40 days of age in these flies (King and Tower, 1999), and the resulting increase was of $\geq 150 \%$.

Interestingly, fly strains genetically selected for their increased longevity display increased $h s p 22 \mathrm{mRNA}$ at the beginning of adulthood comparatively to short-lived strains (Kurapati et al., 2000; Zhao et al., 2005b). These flies were also more resistant to heat-shock and were shown to have a quicker heatshock response than short-lived flies (Zhao et al., 2005b) suggesting a beneficial role of Hsp22 during aging (Kurapati et al., 2000; Zhao et al., 2005b). This was further confirmed by overexpression and down-regulation studies (see Hsp22 OverExpression Increases Longevity and Resistance to Stress and Absence of Hsp22 Expression Decreases Lifespan and Resistance to Stress, Morrow et al., 2004a,b). This positive correlation between the $h s p 22$ mRNA level and lifespan likely indicates a more effective stress response and is consistent with a report showing a positive correlation between the level of induction of a shsp reporter in response to stress and the remaining lifespan in Caenorhabditis elegans (Rea et al., 2005; Yang and Tower, 2009).

\section{Hsp22 Expression Partially Predicts the Remaining Lifespan of Flies}

Due to its stress-inducibility (Colinet et al., 2010; Hirano et al., 2012; Landis et al., 2012; Morrow and Tanguay, 2015) and to the fact that the onset of Hsp22 protein induction is near the beginning of the period of rapid death in the fly population (King and Tower, 1999), the ability of Hsp22 to be an aging biomarker was investigated using transgenic flies expressing the green fluorescent protein (GFP) driven by an $h s p 22$ promoter (hsp22-GFP; Yang and Tower, 2009). It was shown that in a given strain, flies that were robustly expressing the hsp22-GFP transgene at younger adult age than their counterpart tended to die sooner. In this case, the abnormal level of hsp22-GFP transgene expression would be indicative of the high level of stress experienced by a given individual and would represent that particular individual's susceptibility to stress and failing homeostasis and as such could serve as a stress biomarker announcing imminent mortality (Yang and Tower, 2009). While this may seem contradictory to other studies on the beneficial effects of Hsp22 on longevity (Kurapati et al., 2000; Morrow et al., 2004b; Zhao etal., 2005b), it may only represent the importance to express Hsp22 early in development to observe its effect on lifespan. Unfortunately no data on mRNA/protein level of $h s p 22$ are available for the long-lived strains harboring increased levels of $h s p 22$ mRNA early in development (see Hsp22 is Preferentially Up-Regulated During Aging, Kurapati et al., 2000; Zhao et al., 2005b). However, studies using over-expression of Hsp22 have clearly shown that it must be expressed before 4 days of age to confer an increased longevity (Bhole et al., 2004; Morrow et al., 2004b). Moreover, the sensitivity of GFP detection technique may not favor the detection of weak/transient hsp22-GFP expression and therefore emphasis on more robust 
expression. In the same way, Hsp22 protein expression driven in adult motorneurons was not observable by western blots of whole fly homogenate but was still able to mediate lifespan increase (Morrow et al., 2004b). Together these data suggest that the cell-types in which Hsp22 is expressed and the timing of its expression are important factors in its beneficial effect on aging and that robust expression of Hsp22 at the whole organism level may reflects intensive stress and failing homeostasis.

\section{Hsp22 Expression is Modulated by Factors Influencing Longevity}

In the course of understanding the aging process, different proteins, and pathways have been shown to influence lifespan. Interestingly, in some cases the modulation of Hsp22 expression was also reported.

\section{dFoxo as a Regulator of Hsp22 Expression}

The up-regulation of Jun- $N$-terminal Kinase pathway and the down-regulation of the insulin/IGF pathway converge to the transcription factor Foxo to increase lifespan and stress tolerance (Tatar et al., 2001; Wang et al., 2003, 2005; Accili and Arden, 2004; Giannakou and Partridge, 2007). In D. melanogaster, dFoxo has been shown to regulate the expression of Hsp22 together with Hsp23, CG14207, 1(2)efl, Hsp70, Hsp40, Hsp90, and Hop (Wang et al., 2005; Harvey et al., 2008; Hull-Thompson et al., 2009; Demontis and Perrimon, 2010). Hsp22, Hsp23, and 1(2)efl increase longevity upon over-expression and it was therefore proposed that they are, at least in part, involved in the lifespan extension mediated by dFoxo (Morrow et al., 2004b; Wang et al., 2005; Tanguay and Morrow, 2008). Accordingly, it was shown that dFoxo null flies have a reduced lifespan as well as a reduced age-induced expression of 1(2)efl (Shen and Tower, 2010) and Hsp22 (Morrow and Tanguay, 2015).

\section{Hsp22 Expression is Coordinated with the Life Promoting Protein dDnmt2}

In flies, dDnmt 2 is the only DNA methyl transferase known up to now. Contradictory with its name dDnmt 2 has a relatively poor DNA methyl transferase activity, but it has, however, a rather robust tRNA methyl transferase activity (Schaefer and Lyko, 2010; Schaefer et al., 2010). One of the functions of dDnmt2 is to protect stress-induced cleavage of tRNA in stress granules (Schaefer et al., 2010) and it would also be a life determination gene since it increases lifespan and resistance to oxidative stress upon over-expression and decreases Drosophila lifespan when down-regulated (Lin et al., 2005; Schaefer et al., 2010). Interestingly, only Hsp22, Hsp23, and Hsp26 (and no other life promoting genes such as Inr, chico, metuselah, and SOD) were shown to be expressed similarly to $\mathrm{dDnmt} 2$ (i.e., upregulated when $\mathrm{dDnmt} 2$ is over-expressed or down-regulated when dDnmt2 expression is decreased) suggesting that the lifespan determination of dDnmt2 is interconnected with sHSP expression (Lin et al., 2005).

\section{Hsp22 Expression is Influenced by Histone Methylation and Acetylation}

Histone post-translational modifications are known to control gene transcription. Among the enzymes regulating modifications of histones, the histone demethylase KDM4A has been suggested to regulate longevity gene expression. Indeed, the depletion of KDM4A has been shown to induce cellular senescence in normal fibroblasts (Mallette and Richard, 2012) and to decrease lifespan in flies (Lorbeck et al., 2010). Interestingly, the most down-regulated gene in short-lived KDM4A flies was $h s p 22$ (Lorbeck et al., 2010). A link between Hsp22 expression and histone acetylation has also been observed in flies. Indeed, inhibition of histone deacetylase by trichostatin and sodium butyrate was shown to increase lifespan and promote $h s p 22$ and $h s p 70$ expression (Zhao et al., 2005b). In this case, the binding of hyperacetylated histone $\mathrm{H} 3$ at both promoters was shown to increase accessibility of HSEs to the heat shock factor (Zhao et al., 2005a).

\section{Hsp22 has a Protective Role During Lifespan}

The beneficial role of Hsp22 during aging was shown by overexpression and down-regulation studies in flies and was also demonstrated in human cells.

\section{Hsp22 Over-Expression Increases Longevity and Resistance to Stress}

Using the Gal4-UAS system, it was shown that over-expression of Hsp22 either ubiquitously with the actin driver or in motorneurons with the D42 driver increases resistance to heat and oxidative stresses and longevity by up to $30 \%$ (Morrow et al., 2004b). Moreover, flies over-expressing the sHSP maintained their locomotor activity for a longer time suggesting that Hsp22 over-expression increases the health-span (Morrow et al., 2004b). While the beneficial effect of Hsp22 over-expression on lifespan is clear in this system, the timing of its expression is very important. Indeed, over-expressing the sHSP at the beginning of adulthood instead of the beginning of embryogenesis did not result in any increase of longevity (Bhole et al., 2004).

\section{Absence of Hsp22 Expression Decreases Lifespan and Resistance to Stress}

The three HSEs of the $h s p 22$ promoter are required for the age-induced expression of Hsp22 (King and Tower, 1999). Accordingly, flies that carry a p-element insertion in the hsp22 promoter (in between the HSEs) lack the sHSP expression during aging and consequently have a decreased longevity and resistance to stress (Morrow et al., 2004a).

\section{Hsp22 Increases Population Doubling in Human Fibroblasts}

Ten sHSPs are found in humans and up to now none has been found to reside constitutively inside the mitochondria. Interestingly, over-expression of D. melanogaster Hsp22 in primary human fibroblasts extended their lifespan from 58 population doublings to 84 population doublings and this was 
accompanied by a lower level of the senescence associated $\beta$ galactosidase marker (Wadhwa et al., 2010). While it is clear that Hsp22 was functionally active in human cells, its expression was also shown to increase malignant properties of human cancer cell lines (Wadhwa et al., 2010). In mammals, sHSPs are up-regulated in many different cancer cell types and are often linked to bad prognoses (Boncoraglio et al., 2012; Kampinga and Garrido, 2012). The exact mechanisms by which Hsp22 operate in human cells has not been investigated deeply. However, p53 was shown to co-immunoprecipitate with Hsp22 and accordingly, p53 was found in the mitochondria of Hsp22 over-expressing cells (Wadhwa et al., 2010).

\section{Hsp22 Over-Expression Triggers Changes in Gene Transcription}

Consistent with the extent of Hsp22 beneficial effect at the organismal level, Hsp22 over-expression was shown to alter gene transcription. Indeed, transcripts from protein involved in multiple functions were shown to be expressed differently in Hsp22 overexpressing flies, notably genes of the ETC, and genes involved in protein translation (Kim et al., 2010). The mechanism by which a mitochondrial sHSP can alter gene transcription is not clear, but is likely to result from an indirect effect and therefore probably involves other proteins and/or messengers. Mitochondria are in constant communication with the nucleus to adjust gene expression as a response to altered metabolic demand and stress (Haynes et al., 2007; Haynes and Ron, 2010; Runkel et al., 2014). Therefore, rather then initiating a signaling cascade between mitochondria and nucleus, over-expression of Hsp22 may simply modify the mitochondrial status by insuring proteostasis hence influencing mitochondrial function and integrity.

\section{Hsp22 Involvement in the Mitochondrial Unfolding Protein Response}

Due to its drastic up-regulation upon mitochondrial protein synthesis disruption and following different types of stress, Hsp22 has been proposed to be involved in the mtUPR together with Hsp60 and mitochondrial Hsp70 (Fernandez-Ayala et al., 2010; Tower, 2014; Tower et al., 2014; Morrow and Tanguay, 2015).
The mtUPR is a stress response induced by protein misfolding in the mitochondria that involves mitochondria-to-nucleus signaling (Haynes and Ron, 2010). In Drosophila Hsp22 has been proposed to work in an amplification loop of mtUPR since it can influence its own level of expression (Shen and Tower, 2013; Tower et al., 2014). Interestingly, the link between mtUPR and longevity is similar to the one between Hsp22 and longevity since both have to be induced before adulthood to have a positive effect (Bhole et al., 2004; Morrow et al., 2004b; Durieux et al., 2011; Houtkooper et al., 2013). Moreover, both of them have been associated with health-span in Drosophila (Morrow et al., 2004b; Hill and Van Remmen, 2014).

\section{Hsp22 Expression Reduces Mitochondrial Metabolism}

Using a reporter construct consisting in the promoter of $h s p 22$ fused to GFP, a cell lineage-specific induction of Hsp22 was reported in oenocytes (liver-like cells) during aging (Tower et al., 2014). Interestingly, two genes were found to increase the preferential expression of the $h s p 22-\mathrm{GFP}$ reporter construct during aging, namely MnSOD and Hsp22 itself (Tower et al., 2014). This link between MnSOD and Hsp22 expression was also observed in another study aimed at identifying the changes in gene expression in long-lived flies over-expressing MnSOD (Curtis et al., 2007). Oenocytes that express $h s p 22-\mathrm{GFP}$ reporter were shown to accumulate less age pigment and to have lower levels of oxidative stress suggesting that Hsp22 could prevent age-induced damages by reducing mitochondrial metabolism (Tower et al., 2014). Interestingly, the reduction of the mitochondrial metabolism by Hsp22 is also supported by preliminary data from our lab that show the down-regulation of multiple isoforms of proteins from the ETC and Krebs cycle among others upon Hsp22 over-expression (Morrow et al., submitted).

\section{Concluding Remarks}

The suggested effects of Hsp22 on mitochondria are summarized in Figure 1. As mentioned above, Hsp22 over-expression has

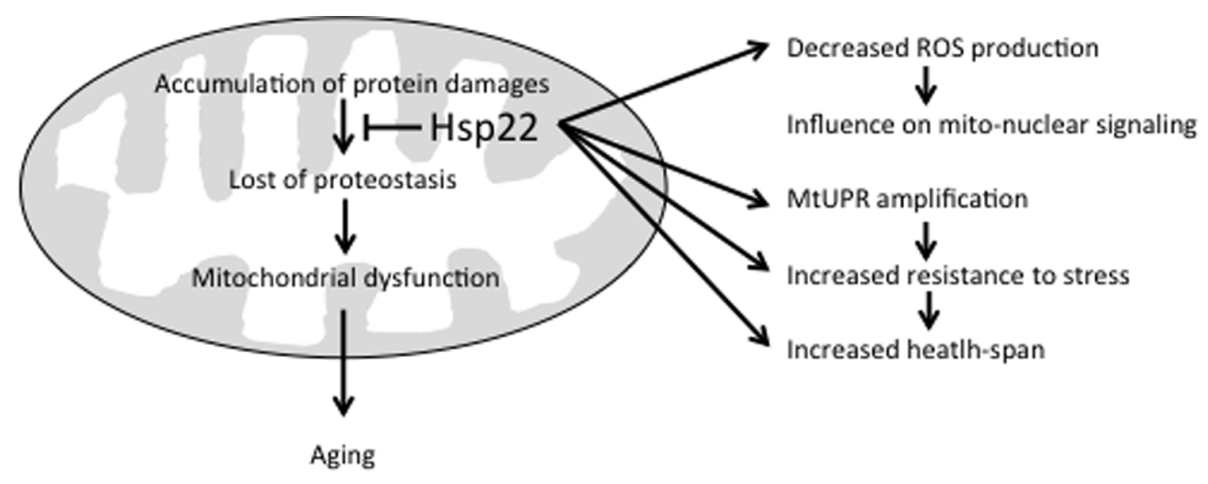

FIGURE 1 | Beneficial effects of Hsp22 on mitochondria. See text for explanation. 
been shown to increase resistance to stress and healthspan (Morrow et al., 2004a,b). This can be achieved directly by preventing the accumulation of protein damages in mitochondria through its chaperone activity (Morrow et al., 2006) and/or indirectly by amplifying mtUPR signaling and subsequent expression of other chaperones and proteases (Haynes and Ron, 2010; Shen and Tower, 2013; Tower et al., 2014). The fact that a reduced mitochondrial metabolism has been associated with Hsp22 expression suggests that this sHSP may also influence mitochondria-to-nucleus signaling through a decreased ROS production (Tower, 2014; Tower et al., 2014).

Drosophila melanogaster Hsp22 is one of the few sHSPs found inside mitochondria independently of the cellular environment together with plants mitochondrial sHSPs (Waters, 2013) and C. elegans Hsp17 (Ezemaduka et al., 2014). The situation in mammals is different as all sHSPs are mainly located in the cytoplasm and shuttles to the different organelles (Nakagawa et al., 2001; van den IJssel et al., 2003; Bryantsev et al., 2007; den Engelsman et al., 2013; Marunouchi et al., 2013). This is notably the case for HSPB1, HSPB2, HSPB5, and HSPB8 that have been shown to shuttle to mitochondria in conditions of oxidative stress (Nakagawa et al., 2001; Jin et al., 2008; Marunouchi et al., 2013). As a general molecular chaperone,

\section{References}

Accili, D., and Arden, K. C. (2004). FoxOs at the crossroads of cellular metabolism, differentiation, and transformation. Cell 117, 421-426. doi: 10.1016/S00928674(04)00452-0

Acunzo, J., Katsogiannou, M., and Rocchi, P. (2012). Small heat shock proteins HSP27 (HspB1), alphaB-crystallin (HspB5) and HSP22 (HspB8) as regulators of cell death. Int. J. Biochem. Cell Biol. 44, 1622-1631. doi: 10.1016/j.biocel.2012.04.002

Bereiter-Hahn, J. (2014). Mitochondrial dynamics in aging and disease. Prog. Mol. Biol. Transl. Sci. 127, 93-131. doi: 10.1016/B978-0-12-394625-6. 00004-0

Bhole, D., Allikian, M. J., and Tower, J. (2004). Doxycycline-regulated overexpression of hsp22 has negative effects on stress resistance and life span in adult Drosophila melanogaster. Mech. Ageing Dev. 125, 651-663. doi: 10.1016/j.mad.2004.08.010

Bissonnette, S. A., Rivera-Rivera, I., Sauer, R. T., and Baker, T. A. (2010). The IbpA and IbpB small heat-shock proteins are substrates of the AAA+ lon protease. Mol. Microbiol. 75, 1539-1549. doi: 10.1111/j.1365-2958.2010. 07070.x

Bohovych, I., Chan, S. S., and Khalimonchuk, O. (2014). Mitochondrial protein quality control: the mechanisms guarding mitochondrial health. Antioxid. Redox Signal. doi: 10.1089/ars.2014.6199 [Epub ahead of print].

Boncoraglio, A., Minoia, M., and Carra, S. (2012). The family of mammalian small heat shock proteins (HSPBs): implications in protein deposit diseases and motor neuropathies. Int. J. Biochem. Cell Biol. 44, 1657-1669. doi: 10.1016/j.biocel.2012.03.011

Bozaykut, P., Ozer, N. K., and Karademir, B. (2014). Regulation of protein turnover by heat shock proteins. Free Radic Biol. Med. 77C, 195-209. doi: 10.1016/j.freeradbiomed.2014.08.012

Bratic, A., and Larsson, N. G. (2013). The role of mitochondria in aging. J. Clin. Invest. 123, 951-957. doi: 10.1172/JCI64125

Bryantsev, A. L., Kurchashova, S. Y., Golyshev, S. A., Polyakov, V. Y., Wunderink, H. F., Kanon, B., et al. (2007). Regulation of stress-induced intracellular sorting and chaperone function of Hsp27 (HspB1) in mammalian cells. Biochem. J. 407, 407-417. doi: 10.1042/BJ20070195

Cobb, B. A., and Petrash, J. M. (2000). Characterization of alpha-crystallin-plasma membrane binding. J. Biol. Chem. 275, 6664-6672. doi: 10.1074/jbc.275.9.6664
Hsp22 may have multiple clients inside the mitochondria and this may account for all the differences observed in flies overexpressing it as well as explain its functionality in orthologous system. Additionally to its role in mitochondrial proteostasis and mtUPR, Hsp22 could help maintain mitochondrial inner membrane integrity in a way similar to what has been observed for the mitochondrial sHSP of C. elegans. Indeed, when over-expressed in bacteria, ceHsp17 was shown to maintain cell envelope integrity at lethal temperatures by associating with bacterial inner membrane (Ezemaduka et al., 2014). Other sHSPs such as Mycobacterium tuberculosis Hsp16.3, Synechocystis Hsp17, and mammalian HSPB5 have been found to be associated with membranes and confer protection (Horvath et al., 1998; Cobb and Petrash, 2000; Torok et al., 2001; Zhang et al., 2005). While we have gained some important clues on the effect of Hsp22 on mitochondrial function, there is still a lot to do to understand exactly how this bona fide chaperone influences longevity and resistance to stress.

\section{Acknowledgment}

This work was supported by a grant from the Canadian Institutes of Health Research to RMT.

Colinet, H., Lee, S. F., and Hoffmann, A. (2010). Temporal expression of heat shock genes during cold stress and recovery from chill coma in adult Drosophila melanogaster. FEBS J. 277, 174-185. doi: 10.1111/j.1742-4658.2009. 07470.x

Curtis, C., Landis, G. N., Folk, D., Wehr, N. B., Hoe, N., Waskar, M., et al. (2007). Transcriptional profiling of MnSOD-mediated lifespan extension in Drosophila reveals a species-general network of aging and metabolic genes. Genome Biol. 8, R262. doi: 10.1186/gb-2007-8-12-r262

Demontis, F., and Perrimon, N. (2010). FOXO/4E-BP signaling in Drosophila muscles regulates organism-wide proteostasis during aging. Cell 143, 813-825. doi: 10.1016/j.cell.2010.10.007

den Engelsman, J., Van De Schootbrugge, C., Yong, J., Pruijn, G. J., and Boelens, W. C. (2013). Pseudophosphorylated alphaB-crystallin is a nuclear chaperone imported into the nucleus with help of the SMN complex. PLoS ONE 8:e73489. doi: 10.1371/journal.pone.0073489

Durieux, J., Wolff, S., and Dillin, A. (2011). The cell-non-autonomous nature of electron transport chain-mediated longevity. Cell 144, 79-91. doi: 10.1016/j.cell.2010.12.016

Ezemaduka, A. N., Yu, J., Shi, X., Zhang, K., Yin, C. C., Fu, X., et al. (2014). A small heat shock protein enables Escherichia coli to grow at a lethal temperature of 50 degrees C conceivably by maintaining cell envelope integrity. J. Bacteriol. 196, 2004-2011. doi: 10.1128/JB.01473-14

Fernandez-Ayala, D. J., Chen, S., Kemppainen, E., O’Dell, K. M., and Jacobs, H. T. (2010). Gene expression in a Drosophila model of mitochondrial disease. PLoS ONE 5:e8549. doi: 10.1371/journal.pone.0008549

Fu, X. (2014). Chaperone function and mechanism of small heat-shock proteins. Acta Biochim. Biophys. Sin. 46, 347-356. doi: 10.1093/abbs/gmt152

Giannakou, M. E., and Partridge, L. (2007). Role of insulin-like signalling in Drosophila lifespan. Trends Biochem. Sci. 32, 180-188. doi: 10.1016/j.tibs.2007.02.007

Girardot, F., Lasbleiz, C., Monnier, V., and Tricoire, H. (2006). Specific age-related signatures in Drosophila body parts transcriptome. BMC Genomics 7:69. doi: 10.1186/1471-2164-7-69

Goldbaum, O., Riedel, M., Stahnke, T., and Richter-Landsberg, C. (2009). The small heat shock protein HSP25 protects astrocytes against stress induced by proteasomal inhibition. Glia 57, 1566-1577. doi: 10.1002/glia.20870

Harman, D. (1956). Aging: a theory based on free radical and radiation chemistry. J. Gerontol. 11, 298-300. doi: 10.1093/geronj/11.3.298 
Harvey, K. F., Mattila, J., Sofer, A., Bennett, F. C., Ramsey, M. R., Ellisen, L. W., et al. (2008). FOXO-regulated transcription restricts overgrowth of Tsc mutant organs. J. Cell Biol. 180, 691-696. doi: 10.1083/jcb.200710100

Haslbeck, M., Franzmann, T., Weinfurtner, D., and Buchner, J. (2005). Some like it hot: the structure and function of small heat-shock proteins. Nat. Struct. Mol. Biol. 12, 842-846. doi: 10.1038/nsmb993

Haynes, C. M., Petrova, K., Benedetti, C., Yang, Y., and Ron, D. (2007). ClpP mediates activation of a mitochondrial unfolded protein response in C. elegans. Dev. Cell 13, 467-480. doi: 10.1016/j.devcel.2007.07.016

Haynes, C. M., and Ron, D. (2010). The mitochondrial UPR - protecting organelle protein homeostasis. J. Cell Sci. 123, 3849-3855. doi: 10.1242/jcs.075119

Hepple, R. T. (2014). Mitochondrial involvement and impact in aging skeletal muscle. Front. Aging Neurosci. 6:211. doi: 10.3389/fnagi.2014.00211

Hill, S., and Van Remmen, H. (2014). Mitochondrial stress signaling in longevity: a new role for mitochondrial function in aging. Redox Biol. 2, 936-944. doi: 10.1016/j.redox.2014.07.005

Hirano, Y., Kuriyama, Y., Miyashita, T., Horiuchi, J., and Saitoe, M. (2012). Reactive oxygen species are not involved in the onset of age-related memory impairment in Drosophila. Genes Brain Behav. 11, 79-86. doi: 10.1111/j.1601183X.2011.00748.x

Horvath, I., Glatz, A., Varvasovszki, V., Torok, Z., Pali, T., Balogh, G., et al. (1998). Membrane physical state controls the signaling mechanism of the heat shock response in Synechocystis PCC 6803: identification of hsp17 as a "fluidity gene". Proc. Natl. Acad. Sci. U.S.A. 95, 3513-3518. doi: 10.1073/pnas.95.7.3513

Houtkooper, R. H., Mouchiroud, L., Ryu, D., Moullan, N., Katsyuba, E., Knott, G., et al. (2013). Mitonuclear protein imbalance as a conserved longevity mechanism. Nature 497, 451-457. doi: 10.1038/nature12188

Hull-Thompson, J., Muffat, J., Sanchez, D., Walker, D. W., Benzer, S., Ganfornina, M. D., et al. (2009). Control of metabolic homeostasis by stress signaling is mediated by the lipocalin NLaz. PLoS Genet. 5:e1000460. doi: 10.1371/journal.pgen. 1000460

Jin, J. K., Whittaker, R., Glassy, M. S., Barlow, S. B., Gottlieb, R. A., and Glembotski, C. C. (2008). Localization of phosphorylated alphaB-crystallin to heart mitochondria during ischemia-reperfusion. Am. J. Physiol. Heart Circ. Physiol. 294, H337-H344. doi: 10.1152/ajpheart.00881.2007

Kampinga, H. H., and Garrido, C. (2012). HSPBs: small proteins with big implications in human disease. Int. J. Biochem. Cell Biol. 44, 1706-1710. doi: 10.1016/j.biocel.2012.06.005

Karagoz, G. E., and Rudiger, S. G. (2015). Hsp90 interaction with clients. Trends Biochem. Sci. 40, 117-125. doi: 10.1016/j.tibs.2014.12.002

Kim, H., Morrow, G., Westwood, T. J., Michaud, S., and Tanguay, R. M. (2010). Gene expression profiling implicates OXPHOS complexes in aging and lifespan extension in flies overexpressing a small mitochondrial chaperone, Hsp22. J. Exp. Gerontol. 45, 611-620. doi: 10.1016/j.exger.2009.12.012

King, V., and Tower, J. (1999). Aging-specific expression of Drosophila hsp22. Dev. Biol. 207, 107-118. doi: 10.1006/dbio.1998.9147

Kotiadis, V. N., Duchen, M. R., and Osellame, L. D. (2014). Mitochondrial quality control and communications with the nucleus are important in maintaining mitochondrial function and cell health. Biochim. Biophys. Acta 1840, 12541265. doi: 10.1016/j.bbagen.2013.10.041

Kurapati, R., Passananti, H. B., Rose, M. R., and Tower, J. (2000). Increased hsp22 RNA levels in Drosophila lines genetically selected for increased longevity. J. Gerontol. A Biol. Sci. Med. Sci. 55, B552-B559. doi: 10.1093/gerona/55.11.B552

Landis, G. N., Abdueva, D., Skvortsov, D., Yang, J., Rabin, B. E., Carrick, J., et al. (2004). Similar gene expression patterns characterize aging and oxidative stress in Drosophila melanogaster. Proc. Natl. Acad. Sci. U.S.A. 101, 7663-7668. doi: 10.1073/pnas.0307605101

Landis, G., Shen, J., and Tower, J. (2012). Gene expression changes in response to aging compared to heat stress, oxidative stress and ionizing radiation in Drosophila melanogaster. Aging (Albany NY) 4, 768-789.

Lin, M. J., Tang, L. Y., Reddy, M. N., and Shen, C. K. (2005). DNA methyltransferase gene dDnmt 2 and longevity of Drosophila. J. Biol. Chem. 280, 861-864. doi: 10.1074/jbc.C400477200

Lorbeck, M. T., Singh, N., Zervos, A., Dhatta, M., Lapchenko, M., Yang, C., et al. (2010). The histone demethylase Dmel $\backslash \mathrm{Kdm} 4 \mathrm{~A}$ controls genes required for life span and male-specific sex determination in Drosophila. Gene 450, 8-17. doi: 10.1016/j.gene.2009.09.007
Mallette, F. A., and Richard, S. (2012). JMJD2A promotes cellular transformation by blocking cellular senescence through transcriptional repression of the tumor suppressor CHD5. Cell Rep. 2, 1233-1243. doi: 10.1016/j.celrep.2012. 09.033

Marunouchi, T., Abe, Y., Murata, M., Inomata, S., Sanbe, A., Takagi, N., et al. (2013). Changes in small heat shock proteins HSPB1, HSPB5 and HSPB8 in mitochondria of the failing heart following myocardial infarction in rats. Biol. Pharm. Bull. 36, 529-539. doi: 10.1248/bpb.b12-00796

McHaourab, H. S., Godar, J. A., and Stewart, P. L. (2009). Structure and mechanism of protein stability sensors: chaperone activity of small heat shock proteins. Biochemistry 48, 3828-3837. doi: 10.1021/bi900212j

Michaud, S., Morrow, G., Marchand, J., and Tanguay, R. M. (2002). Drosophila small heat shock proteins: cell and organelle-specific chaperones? Prog. Mol. Subcell. Biol. 28, 79-101. doi: 10.1007/978-3-642-56348-5_5

Morrow, G., Battistini, S., Zhang, P., and Tanguay, R. M. (2004a). Decreased lifespan in the absence of expression of the mitochondrial small heat shock protein Hsp22 in Drosophila. J. Biol. Chem. 279, 43382-43385. doi: 10.1074/jbc.C400357200

Morrow, G., Samson, M., Michaud, S., and Tanguay, R. M. (2004b). Overexpression of the small mitochondrial Hsp22 extends Drosophila life span and increases resistance to oxidative stress. FASEB J. 18, 598-599. doi: 10.1096/fj.03-0860fje

Morrow, G., Heikkila, J. J., and Tanguay, R. M. (2006). Differences in the chaperone-like activities of the four main small heat shock proteins of Drosophila melanogaster. Cell Stress Chaperones 11, 51-60. doi: 10.1379/CSC-166.1

Morrow, G., Inaguma, Y., Kato, K., and Tanguay, R. M. (2000). The small heat shock protein Hsp22 of Drosophila melanogaster is a mitochondrial protein displaying oligomeric organization. J. Biol. Chem. 275, 31204-31210. doi: 10.1074/jbc.M002960200

Morrow, G., and Tanguay, R. M. (2015). "Drosophila small heat shock proteins: an update on their features and functions," in The Big Book of sHSPs, eds R. M. Tanguay and L. E. Hightower (Cham: Springer International Publishing AG).

Nakagawa, M., Tsujimoto, N., Nakagawa, H., Iwaki, T., Fukumaki, Y., and Iwaki, A. (2001). Association of HSPB2, a member of the small heat shock protein family, with mitochondria. Exp. Cell Res. 271, 161-168. doi: 10.1006/excr.2001.5362

Osellame, L. D., and Duchen, M. R. (2014). Quality control gone wrong: mitochondria, lysosomal storage disorders and neurodegeneration. Br. J. Pharmacol. 171, 1958-1972. doi: 10.1111/bph.12453

Priya, S., Sharma, S. K., and Goloubinoff, P. (2013). Molecular chaperones as enzymes that catalytically unfold misfolded polypeptides. FEBS Lett. 587, 19811987. doi: 10.1016/j.febslet.2013.05.014

Rea, S. L., Wu, D., Cypser, J. R., Vaupel, J. W., and Johnson, T. E. (2005). A stresssensitive reporter predicts longevity in isogenic populations of Caenorhabditis elegans. Nat. Genet. 37, 894-898. doi: 10.1038/ng1608

Runkel, E. D., Baumeister, R., and Schulze, E. (2014). Mitochondrial stress: balancing friend and foe. Exp. Gerontol. 56, 194-201. doi: 10.1016/j.exger.2014.02.013

Ryabova, N. A., Marchenkov, V. V., Marchenkova, S. Y., Kotova, N. V., and Semisotnov, G. V. (2013). Molecular chaperone GroEL/ES: unfolding and refolding processes. Biochemistry (Mosc) 78, 1405-1414. doi: $10.1134 /$ S0006297913130038

Saibil, H. (2013). Chaperone machines for protein folding, unfolding and disaggregation. Nat. Rev. Mol. Cell Biol. 14, 630-642. doi: 10.1038/nrm3658

Schaefer, M., and Lyko, F. (2010). Solving the Dnmt2 enigma. Chromosoma 119, 35-40. doi: 10.1007/s00412-009-0240-6

Schaefer, M., Pollex, T., Hanna, K., Tuorto, F., Meusburger, M., Helm, M., et al. (2010). RNA methylation by Dnmt2 protects transfer RNAs against stressinduced cleavage. Genes Dev. 24, 1590-1595. doi: 10.1101/gad.586710

Scheibye-Knudsen, M., Fang, E. F., Croteau, D. L., Wilson, D. M. III, and Bohr, V. A. (2015). Protecting the mitochondrial powerhouse. Trends Cell Biol. 25, 158-170. doi: 10.1016/j.tcb.2014.11.002

Shen, J., and Tower, J. (2010). Drosophila foxo acts in males to cause sexualdimorphism in tissue-specific p53 life span effects. Exp. Gerontol. 45, 97-105. doi: 10.1016/j.exger.2009.10.009

Shen, J., and Tower, J. (2013). Aging, MnSOD, and hormesis mechanisms converge on liver mUPR. Cell Cycle 12, 3237-3238. doi: 10.4161/cc.26354

Tanguay, R. M., and Morrow, G. (2008). "Neuronal expression of small heat shock proteins influences longevity and resistance to oxidative stress," in Heat Shock Proteins and the Brain: Implications for Neurodegenerative Diseases and 
Neuroprotection, eds A. A. A. Asea and I. R. Brown (New York: Springer), 319-336. doi: 10.1007/978-1-4020-8231-3_16

Tatar, M., Kopelman, A., Epstein, D., Tu, M. P., Yin, C. M., and Garofalo, R. S. (2001). A mutant Drosophila insulin receptor homolog that extends life-span and impairs neuroendocrine function. Science 292, 107-110. doi: 10.1126/science. 1057987

Torok, Z., Goloubinoff, P., Horvath, I., Tsvetkova, N. M., Glatz, A., Balogh, G., et al. (2001). Synechocystis HSP17 is an amphitropic protein that stabilizes heat-stressed membranes and binds denatured proteins for subsequent chaperone-mediated refolding. Proc. Natl. Acad. Sci. U.S.A. 98, 3098-3103. doi: 10.1073/pnas.051619498

Tower, J. (2014). Mitochondrial maintenance failure in aging and role of sexual dimorphism. Arch. Biochem. Biophys. doi: 10.1016/j.abb.2014.10.008 [Epub ahead of print].

Tower, J., Landis, G., Gao, R., Luan, A., Lee, J., and Sun, Y. (2014). Variegated expression of Hsp22 transgenic reporters indicates cell-specific patterns of aging in Drosophila oenocytes. J. Gerontol. A Biol. Sci. Med. Sci. 69, 253-259. doi: 10.1093/gerona/glt078

Treweek, T. M., Meehan, S., Ecroyd, H., and Carver, J. A. (2015). Small heat-shock proteins: important players in regulating cellular proteostasis. Cell Mol. Life Sci. 72, 429-451. doi: 10.1007/s00018-014-1754-5

van den IJssel, P., Wheelock, R., Prescott, A., Russell, P., and Quinlan, R. A. (2003). Nuclear speckle localisation of the small heat shock protein alpha B-crystallin and its inhibition by the R120G cardiomyopathy-linked mutation. Exp. Cell Res. 287, 249-261. doi: 10.1016/S0014-4827(03)00092-2

Van Raamsdonk, J. M., and Hekimi, S. (2009). Deletion of the mitochondrial superoxide dismutase sod-2 extends lifespan in Caenorhabditis elegans. PLoS Genet 5:e1000361. doi: 10.1371/journal.pgen.1000361

Van Raamsdonk, J. M., and Hekimi, S. (2012). Superoxide dismutase is dispensable for normal animal lifespan. Proc. Natl. Acad. Sci. U.S.A. 109, 5785-5790. doi: $10.1073 /$ pnas.1116158109

Vos, M. J. (2009). Small Heat Shock Proteins: Implications for Neurodegeneration and Longevity. Dissertation, Department of Cell Biology, University of Groningen, Groningen.

Vos, M. J., Hageman, J., Carra, S., and Kampinga, H. H. (2008). Structural and functional diversities between members of the human HSPB, HSPH, HSPA, and DNAJ chaperone families. Biochemistry 47, 7001-7011. doi: 10.1021/bi800639z

Wadhwa, R., Ryu, J., Gao, R., Choi, I. K., Morrow, G., Kaur, K., et al. (2010). Proproliferative functions of Drosophila small mitochondrial heat shock protein 22 in human cells. J. Biol. Chem. 285, 3833-3839. doi: 10.1074/jbc.M109.080424

Wang, M. C., Bohmann, D., and Jasper, H. (2003). JNK signaling confers tolerance to oxidative stress and extends lifespan in Drosophila. Dev. Cell 5, 811-816. doi: 10.1016/S1534-5807(03)00323-X
Wang, M. C., Bohmann, D., and Jasper, H. (2005). JNK extends life span and limits growth by antagonizing cellular and organism-wide responses to insulin signaling. Cell 121, 115-125. doi: 10.1016/j.cell.2005. 02.030

Waters, E. R. (2013). The evolution, function, structure, and expression of the plant sHSPs. J. Exp. Bot. 64, 391-403. doi: 10.1093/jxb/ers355

Yang, J., and Tower, J. (2009). Expression of hsp22 and hsp70 transgenes is partially predictive of Drosophila survival under normal and stress conditions. J. Gerontol. A Biol. Sci. Med. Sci. 64, 828-838. doi: 10.1093/gerona/ glp054

Yee, C., Yang, W., and Hekimi, S. (2014). The intrinsic apoptosis pathway mediates the pro-longevity response to mitochondrial ROS in C. elegans. Cell 157, 897-909. doi: 10.1016/j.cell.2014.02.055

Zhang, H., Fu, X., Jiao, W., Zhang, X., Liu, C., and Chang, Z. (2005). The association of small heat shock protein Hsp16.3 with the plasma membrane of Mycobacterium tuberculosis: dissociation of oligomers is a prerequisite. Biochem. Biophys. Res. Commun. 330, 1055-1061. doi: 10.1016/j.bbrc.2005.03.092

Zhao, Y., Lu, J., Sun, H., Chen, X., Huang, W., Tao, D., et al. (2005a). Histone acetylation regulates both transcription initiation and elongation of hsp22 gene in Drosophila. Biochem. Biophys. Res. Commun. 326, 811-816. doi: 10.1016/j.bbrc.2004.11.118

Zhao, Y., Sun, H., Lu, J., Li, X., Chen, X., Tao, D., et al. (2005b). Lifespan extension and elevated hsp gene expression in Drosophila caused by histone deacetylase inhibitors. J. Exp. Biol. 208, 697-705. doi: 10.1242/jeb.01439

Ziegler, D. V., Wiley, C. D., and Velarde, M. C. (2014). Mitochondrial effectors of cellular senescence: beyond the free radical theory of aging. Aging Cell. doi: 10.1111/acel.12287

Zou, S., Meadows, S., Sharp, L., Jan, L. Y., and Jan, Y. N. (2000). Genomewide study of aging and oxidative stress response in Drosophila melanogaster. Proc. Natl. Acad. Sci. U.S.A. 97, 13726-13731. doi: 10.1073/pnas.2604 96697

Conflict of Interest Statement: The authors declare that the research was conducted in the absence of any commercial or financial relationships that could be construed as a potential conflict of interest.

Copyright (C) 2015 Morrow and Tanguay. This is an open-access article distributed under the terms of the Creative Commons Attribution License (CC BY). The use, distribution or reproduction in other forums is permitted, provided the original author(s) or licensor are credited and that the original publication in this journal is cited, in accordance with accepted academic practice. No use, distribution or reproduction is permitted which does not comply with these terms. 